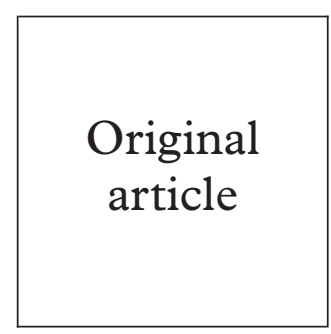

\title{
Trends in undiagnosed HIV-1 infection among attenders at genitourinary medicine clinics, England, Wales, and Northern Ireland: 1990-6
}

\author{
I Simms, P Rogers, M Catchpole, C A McGarrigle, A Nicoll, on behalf of the collaborative \\ group ${ }^{\star}$
}

\begin{abstract}
Objective: To describe trends in seroprevalence of undiagnosed HIV-1 infection among attenders at 15 genitourinary medicine clinics in England, Wales, and Northern Ireland between 1990 and 1996.
\end{abstract}

Method: Prospective, cross sectional sentinel serosurvey. Unlinked anonymous testing of remnant serum drawn for routine syphilis screening.

Results: In 1996, the seroprevalence of undiagnosed HIV-1 infection was 5\% in homosexual men, $0.48 \%$ in heterosexual men, and $0.33 \%$ in heterosexual women. Between 1990 and 1996, there was a significant linear decrease in the seroprevalence of undiagnosed HIV-1 infection among homosexual and bisexual men within and outside London $(p<0.0001 ; p=0.0141)$, equivalent to yearly decreases of $7.65 \%$ and $10.73 \%$ respectively. However, seroprevalence among homosexual and bisexual men under 25 years of age did not decline either inside or outside London. Seroprevalence among heterosexual men declined outside London $(p<0.005)$, equivalent to an average annual decrease of $14.54 \%$. There was a significant increase among male heterosexuals inside London $(p<0.05)$ equivalent to a $8.09 \%$ increase per annum. Seroprevalence over time was unchanging among female heterosexuals both inside and outside London. Seroprevalence was significantly higher among those who injected drugs than those who did not report injecting in the following groups: homosexual and bisexual males within London $(\mathrm{p}<0.005)$, male heterosexuals both within and outside London $(p<0.05 ; \mathrm{p}<0.05)$ and female heterosexuals within London $(\mathrm{p}<0.05)$.

Conclusions: The study highlights a significant burden of undiagnosed HIV-1 infection more than 15 years since the HIV epidemic began. Methods of offering HIV testing need to be reassessed to extend the practice of routinely testing for HIV in GUM clinics. HIV transmission among young homosexual and bisexual men continues. The contrasting trends between homosexual and bisexual men, injecting drug users, and heterosexuals attending GUM clinics indicate these groups should be considered separately. The substantial HIV seroprevalence in each group indicates that they should be priorities for targeted HIV prevention.

(Sex Transm Inf 1999;75:332-336)

Keywords: HIV seroprevalence; sexually transmitted diseases; England; Wales

\section{Introduction}

In England, Wales, and Northern Ireland, 83\% (23 660 of the 28361 ) of HIV cases reported up to the end of 1997 were attributed to sexual transmission. ${ }^{1}$ Consequently, UK health campaigns have focused on safer sex as the key to HIV prevention. ${ }^{2}$ The seroprevalence of HIV-1 infection among heterosexual women attending genitourinary medicine (GUM) services is four times that seen among pregnant women. ${ }^{3}$ This, together with the increasing burden of sexually transmitted infections (STIs) seen in GUM clinics, indicate that many attenders remain behaviourally vulnerable to HIV infection. ${ }^{4-6}$ Attenders at GUM clinics are thus a prime sentinel group for monitoring HIV.

The survey of HIV seroprevalence among GUM clinic attenders, set up in 1990 as part of the unlinked anonymous prevalence monitoring programme, ${ }^{7}$ uses an unlinked anonymous methodology to minimise participation bias and records previously diagnosed infections. The seroprevalence of undiagnosed HIV-1 infection can thus be estimated. This analysis was confined to undiagnosed HIV-1 infection for a number of reasons. Quality control studies and preliminary analyses indicated that diagnosed HIV-1 infection was increasingly managed in specialist HIV care outside routine GUM services during the course of the study. Consequently there was a marked decrease in the seroprevalence of diagnosed HIV-1 infection. This bias prevents comparison of the seroprevalence of diagnosed and undiagnosed HIV-1 infection and thus the study was confined to undiagnosed HIV-1 infection which was unaffected by this source of bias.

Previous analyses of this dataset have shown that undiagnosed HIV-1 infection accounts for a substantial proportion of HIV-1 infections seen in GUM clinics and that patients with undiagnosed HIV-1 infection are more likely to have a newly acquired STI that those with diagnosed HIV-1 infection. ${ }^{8}$ HIV infection in people unaware of their HIV positive serostatus is thus an important public health problem, as they are unable to benefit from recent advances in HIV care, and may be the source of ongoing transmission. ${ }^{8}$ The analysis of undiagnosed infection among GUM clinic attenders repre- 
Table 1 Seroprevalence of HIV-1 infection among homosexual and bisexual men

\begin{tabular}{|c|c|c|c|c|c|c|}
\hline & \multicolumn{3}{|l|}{ London } & \multicolumn{3}{|l|}{ Outside London } \\
\hline & $\begin{array}{l}\% \text { HIV-1 } \\
\text { infected (total) }\end{array}$ & $\begin{array}{l}\text { Adjusted } O R^{\star} \\
(95 \% \mathrm{CI})\end{array}$ & $p$ Value & $\begin{array}{l}\% \text { HIV-1 } \\
\text { infected (total) }\end{array}$ & $\begin{array}{l}\text { Adjusted OR* } \\
(95 \% \mathrm{CI})\end{array}$ & $p$ Value \\
\hline Age group & & & $<0.0001$ & & & 0.1239 \\
\hline$<20$ & $4.95(364)$ & $0.82(0.50-1.36)$ & & $0.92(435)$ & $0.44(0.16-1.25)$ & \\
\hline 20 to 24 & $5.83(3226)$ & 1.00 & & $2.16(1624)$ & 1.00 & \\
\hline 25 to 34 & $9.06(10504)$ & $1.71(1.45-2.01)$ & & $2.70(3038)$ & $1.27(0.85-1.90)$ & \\
\hline 35 to 44 & $9.06(4061)$ & $1.77(1.47-2.12)$ & & $2.78(1373)$ & $1.30(0.81-2.07)$ & \\
\hline $45+$ & $6.99(1802)$ & $1.35(1.07-1.71)$ & & $2.19(866)$ & $1.02(0.58-1.80)$ & \\
\hline \multicolumn{7}{|l|}{ IDU } \\
\hline Yes & $13.05(452)$ & $1.65(1.24-2.19)$ & 0.0019 & $1.79(112)$ & $0.68(0.17-2.77)$ & 0.6713 \\
\hline No & $8.12(18314)$ & 1.00 & & $2.42(7060)$ & 1.00 & \\
\hline NA/NR $†$ & $8.82(1191)$ & $1.17(0.94-1.45)$ & & $3.05(164)$ & $1.39(0.56-3.47)$ & \\
\hline \multicolumn{7}{|l|}{ Year } \\
\hline 1990-1 & $9.90(475)$ & 1.00 & 0.0004 & $4.30(93)$ & 1.00 & 0.1462 \\
\hline $1990-2$ & $12.24(915)$ & $1.05(0.73-1.52)$ & & $2.88(278)$ & $0.62(0.18-2.13)$ & \\
\hline 1991-1 & $10.07(1420)$ & $0.85(0.60-1.21)$ & & $2.88(312)$ & $0.56(0.16-1.89)$ & \\
\hline 1991-2 & $9.69(1104)$ & $0.87(0.61-1.26)$ & & $4.38(274)$ & $0.83(0.26-2.71)$ & \\
\hline $1992-1$ & $10.49(915)$ & $0.93(0.64-1.35)$ & & $1.25(401)$ & $0.20(0.05-0.80)$ & \\
\hline $1992-2$ & $9.70(1381)$ & $0.83(0.58-1.18)$ & & $2.94(544)$ & $0.49(0.15-1.57)$ & \\
\hline 1993-1 & $9.84(1138)$ & $0.84(0.58-1.21)$ & & $2.30(740)$ & $0.41(0.13-1.30)$ & \\
\hline 1993-2 & $8.31(1071)$ & $0.71(0.49-1.03)$ & & $3.57(729)$ & $0.62(0.20-1.93)$ & \\
\hline 1994-1 & $8.33(1212)$ & $0.74(0.51-1.07)$ & & $1.93(624)$ & $0.35(0.10-1.16)$ & \\
\hline 1994-2 & $8.31(1806)$ & $0.79(0.56-1.12)$ & & $2.20(682)$ & $0.39(0.12-1.27)$ & \\
\hline 1995-1 & $6.83(2256)$ & $0.66(0.47-0.93)$ & & $2.58(638)$ & $0.45(0.14-1.43)$ & \\
\hline 1995-2 & $6.80(2237)$ & $0.67(0.47-0.94)$ & & $1.44(619)$ & $0.33(0.10-1.10)$ & \\
\hline $1996-1$ & $6.52(2332)$ & $0.63(0.44-0.89)$ & & $1.85(703)$ & $0.30(0.09-1.01)$ & \\
\hline $1996-2$ & $6.08(1695)$ & $0.58(0.40-0.83)$ & & $1.77(679)$ & $0.31(0.09-1.01)$ & \\
\hline
\end{tabular}

*Adjusted for age, IDU, time (as a factor), and centre.

†Not asked or not recorded.

sents a measure of the underlying prevalence of HIV infection. The prevalence of HIV infection in people under 25 years of age approximates to recent transmission of infection. ${ }^{9}$ The aim of this analysis was thus to investigate differences and trends in undiagnosed HIV-1 infection by exposure category using data collected between 1990 and 1996.

\section{Patients and methods}

Between 1990 and 1994, 15 clinics were recruited, seven in London and eight outside London $^{10}$; the data management and laboratory methods have been described previously. $^{3710}$ For each attender, the first specimen tested for syphilis serology within each calendar quarter was eligible for inclusion. Data items collected included the following: sexual orientation, age group $(<20,20-24$, $25-34,35-44$, and 45 and over), known to be infected with HIV before the clinic visit, injecting drug use (IDU), HIV-1 test result from residual specimen, clinic, and quarter and year of attendance. Cases with diagnosed HIV-1 infection (that is, those known to be HIV infected before attendance) were removed from the analysis. The data were stratified by exposure category (homosexual and bisexual male, heterosexual male, and heterosexual female). Data were analysed and presented according to whether clinics were inside or outside London. ${ }^{10}$ The data were aggregated to 6 month periods. A separate analysis was undertaken for those under 25 years of age.

The three exposure categories were analysed separately using a logistic regression model in GLIM4 ${ }^{11}$ All two way interactions between the independent variables were investigated and the smallest adequate model fitted. The baselines for odds ratio calculation were: age 20-24, not known to be an IDU, and the first half of 1990. Trends in prevalence over time were investigated by fitting suitable polynomi- als to a model that included time as a variable. Where overdispersion was found, rescaling was used in the subsequent analyses.

\section{Results}

A total of 315477 attenders were included in the analysis, 2805 of these were found to have undiagnosed HIV-1 infection. Only 1795 $(0.6 \%)$ of attenders objected to the study. These were evenly distributed among the exposure categories, were unlikely to have biased the results, and were excluded from the analysis. $^{12}$ Seroprevalence of undiagnosed HIV-1 infection by exposure category with adjusted odds ratios (OR) (adjusted by age, IDU, time, and centre) together with $95 \%$ confidence intervals (CIs) are shown in tables 1, 2, and 3. In 1996, the seroprevalence of undiagnosed HIV-1 infection was $5 \%$ in homosexual men. $0.48 \%$ in heterosexual men, and $0.33 \%$ in heterosexual women.

\section{ASSOCIATION WITH AGE GROUP}

After adjustment for other factors, significant differences in HIV-1 seroprevalence by age group were seen in all exposure categories. For homosexual and bisexual males within London, seroprevalence of undiagnosed infection was significantly higher than the baseline (the 20-24 year age group) in those aged 25 and over $(p<0.0001)$. Outside London no difference was seen between age groups. For heterosexual men, there were significant differences in HIV-1 seroprevalence by age group both within and outside London $(\mathrm{p}<0.0001$; $\mathrm{p}<0.001$ ), highest seroprevalence being seen in those aged 25 or more. For heterosexual women, the seroprevalence inside London was significantly lower in the under 20 age group $(\mathrm{p}<0.0001)$, whereas outside London it was significantly higher in the 25-34 year age group $(\mathrm{p}<0.0001)$. 
Table 2 Seroprevalence of HIV-1 infection among heterosexual men

\begin{tabular}{|c|c|c|c|c|c|c|}
\hline & \multicolumn{3}{|l|}{ London } & \multicolumn{3}{|l|}{ Outside London } \\
\hline & $\begin{array}{l}\% \text { HIV-1 } \\
\text { infected (total) }\end{array}$ & $\begin{array}{l}\text { Adjusted OR* } \\
(95 \% C I)\end{array}$ & $p$ Value & $\begin{array}{l}\% \text { HIV-1 } \\
\text { infected (total) }\end{array}$ & $\begin{array}{l}\text { Adjusted OR* } \\
(95 \% \mathrm{CI})\end{array}$ & $p$ Value \\
\hline \multicolumn{7}{|l|}{ Age group } \\
\hline$<20$ & $0.23(2196)$ & $0.52(0.21-1.30)$ & $<0.0001$ & $0.08(6483)$ & $1.26(0.46-3.46)$ & 0.0001 \\
\hline 20 to 24 & $0.46(10005)$ & 1.00 & & $0.06(24711)$ & 1.00 & \\
\hline 25 to 34 & $0.96(24882)$ & $2.08(1.51-2.85)$ & & $0.18(37247)$ & $2.97(1.70-5.20)$ & \\
\hline 35 to 44 & $1.30(8667)$ & $2.08(2.04-4.07)$ & & $0.18(14316)$ & $3.09(1.63-5.83)$ & \\
\hline $45+$ & $0.80(4265)$ & $1.78(1.14-2.77)$ & & $0.17(6443)$ & $3.06(1.45-6.43)$ & \\
\hline \multicolumn{7}{|l|}{ IDU } \\
\hline Yes & $2.01(944)$ & $1.92(1.20-3.06)$ & 0.0451 & $0.52(953)$ & $3.86(1.56-9.53)$ & 0.0396 \\
\hline No & $0.85(44400)$ & 1.00 & & $0.14(87582)$ & 1.00 & \\
\hline NA-NR† & $0.88(4671)$ & $1.05(0.73-1.51)$ & & $0.06(1665)$ & $0.54(0.08-3.62)$ & \\
\hline \multicolumn{7}{|l|}{ Year } \\
\hline 1990-1 & $0.79(632)$ & 1.00 & 0.0123 & $0.25(1612)$ & 1.00 & 0.2540 \\
\hline 1990-2 & $0.72(1249)$ & $0.76(0.25-2.29)$ & & $0.29(3841)$ & $0.98(0.31-3.11)$ & \\
\hline 1991-1 & $0.81(1599)$ & $0.84(0.30-2.38)$ & & $0.18(3804)$ & $0.61(0.17-2.12)$ & \\
\hline 1991-2 & $1.23(1377)$ & $1.36(0.50-3.72)$ & & $0.16(3723)$ & $0.51(0.14-1.83)$ & \\
\hline $1992-1$ & $0.72(1112)$ & $0.80(0.26-2.45)$ & & $0.18(5105)$ & $0.62(0.19-2.08)$ & \\
\hline $1992-2$ & $0.46(1971)$ & $0.51(0.17-1.52)$ & & $0.17(7085)$ & $0.52(0.16-1.68)$ & \\
\hline 1993-1 & $0.70(2413)$ & $0.90(0.33-2.48)$ & & $0.10(8789)$ & $0.29(0.08-0.98)$ & \\
\hline 1993-2 & $1.15(3305)$ & $1.47(0.57-3.78)$ & & $0.11(7909)$ & $0.30(0.09-1.04)$ & \\
\hline 1994-1 & $1.16(4121)$ & $1.54(0.60-3.92)$ & & $0.13(7181)$ & $0.33(0.10-1.15)$ & \\
\hline 1994-2 & $0.95(5781)$ & $1.40(0.55-3.57)$ & & $0.15(7833)$ & $0.41(0.12-1.35)$ & \\
\hline 1995-1 & 0.77 (6499) & $1.16(0.46-2.96)$ & & $0.08(7463)$ & $0.23(0.06-0.84)$ & \\
\hline 1995-2 & $0.65(6820)$ & $0.99(0.39-2.54)$ & & $0.13(8618)$ & $0.34(0.10-1.14)$ & \\
\hline $1996-1$ & $0.90(6913)$ & $1.35(0.53-3.40)$ & & $0.10(8981)$ & $0.27(0.08-0.92)$ & \\
\hline $1996-2$ & $1.01(6223)$ & $1.56(0.62-3.94)$ & & $0.13(8252)$ & $0.36(0.11-1.18)$ & \\
\hline
\end{tabular}

*Adjusted for age, IDU, time (as a factor), and centre.

†Not asked or not recorded.

ASSOCIATION WITH INJECTING DRUG USE

A comparison was made between those known to have injected drugs and those who did not report injecting (baseline). Seroprevalence was significantly higher than the baseline among those who injected in the following exposure categories: homosexual and bisexual males within London $(\mathrm{p}<0.005)$, male heterosexuals both within and outside London $(\mathrm{p}<0.05$; $\mathrm{p}<0.05$ ), and female heterosexuals within London $(\mathrm{p}<0.05)$.

TRENDS IN SEROPREVALENCE OF UNDIAGNOSED INFECTION, 1990-6

For homosexual and bisexual men, there was a significant linear decrease over time in undiag- nosed HIV-1 infection both inside and outside London ( $\mathrm{p}<0.001 ; \mathrm{p}<0.05)$, equivalent to yearly decreases of $7.65 \%$ (95\% CL $5.09 \%$ to $10.14 \%$ ) and $10.73 \%$ (95\% CL $2.21 \%$ to $18.51 \%$ ) respectively. There was also a significant linear decrease among male heterosexuals outside London $(\mathrm{p}<0.005)$, equivalent to an annual decrease of $14.54 \%$ (95\% CL $4.85 \%$ to $23.25 \%$ ). However, inside London, there was a significant linear increase in HIV-1 seroprevalence among male heterosexuals $(\mathrm{p}<0.05)$, equivalent to an $8.09 \%$ (95\% CL $1.63 \%$ to $14.96 \%$ ) increase per annum. No trend in HIV-1 seroprevalence was seen for female heterosexuals within or outside London.

Table 3 Seroprevalence of HIV-1 infection among heterosexual women

\begin{tabular}{|c|c|c|c|c|c|c|}
\hline \multirow[b]{2}{*}{ Factor } & \multicolumn{3}{|l|}{ London } & \multicolumn{3}{|l|}{ Outside London } \\
\hline & $\begin{array}{l}\% \text { HIV-1 } \\
\text { infected (total) }\end{array}$ & $\begin{array}{l}\text { Adjusted OR* } \\
(95 \% \mathrm{CI})\end{array}$ & $p$ Value & $\begin{array}{l}\% \text { HIV-1 } \\
\text { infected (total) }\end{array}$ & $\begin{array}{l}\text { Adjusted OR* } \\
(95 \% \mathrm{CI})\end{array}$ & p Value \\
\hline \multicolumn{7}{|l|}{ Age group } \\
\hline$<20$ & $0.22(6040)$ & $0.44(0.24-0.78)$ & \multirow{5}{*}{$<0.0001$} & $0.01(13329)$ & $0.14(0.02-1.01)$ & \multirow{5}{*}{$<0.0001$} \\
\hline 20 to 24 & $0.46(19856)$ & 1.00 & & $0.05(24945)$ & 1.00 & \\
\hline 25 to 34 & $0.61(32555)$ & $1.31(1.01-1.68)$ & & $0.14(26880)$ & $2.79(1.48-5.24)$ & \\
\hline 35 to 44 & $0.46(8784)$ & $0.96(0.66-1.40)$ & & $0.10(9160)$ & $1.92(0.82-4.49)$ & \\
\hline $45+$ & $0.21(2803)$ & $0.45(0.20-1.02)$ & & $0.11(3617)$ & $2.21(0.72-6.77)$ & \\
\hline \multicolumn{7}{|c|}{$0.43(0.20-1.02)$} \\
\hline Yes & $1.39(717)$ & $2.77(1.47-5.22)$ & \multirow{3}{*}{0.0243} & $0.28(354)$ & $3.43(0.48-24.65)$ & \multirow{3}{*}{0.5670} \\
\hline No & $0.48(63438)$ & 1.00 & & $0.08(751265)$ & 1.00 & \\
\hline NA/NR† & $0.58(5883)$ & $1.08(0.73-1.60)$ & & $0.08(2451)$ & $1.29(0.30-5.49)$ & \\
\hline \multicolumn{7}{|l|}{ Year } \\
\hline 1990-1 & $0.48(421)$ & 1.00 & \multirow[t]{14}{*}{0.9274} & $0.31(329)$ & 1.00 & \multirow[t]{14}{*}{0.0971} \\
\hline $1990-2$ & $0.41(2193)$ & $0.72(0.15-3.34)$ & & 0.05 (2099) & $0.08(0.00-1.44)$ & \\
\hline $1991-1$ & $0.50(2408)$ & $0.86(0.19-3.84)$ & & $0.16(3113)$ & $0.30(0.03-2.75)$ & \\
\hline 1991-2 & $0.41(2172)$ & $0.81(0.17-3.76)$ & & $0.20(3021)$ & $0.34(0.04-3.03)$ & \\
\hline $1992-1$ & $0.59(2019)$ & $1.13(0.25-5.07)$ & & $0.02(4320)$ & $0.05(0.00-0.86)$ & \\
\hline $1992-2$ & $0.43(3012)$ & $0.73(0.16-3.25)$ & & $0.13(5940)$ & $0.28(0.03-2.51)$ & \\
\hline $1993-1$ & $0.58(3789)$ & $0.90(0.21-3.86)$ & & $0.11(7459)$ & $0.21(0.02-1.86)$ & \\
\hline $1993-2$ & $0.32(4337)$ & $0.56(0.12-2.45)$ & & $0.07(7131)$ & $0.13(0.01-1.24)$ & \\
\hline $1994-1$ & $0.51(5337)$ & $0.79(0.18-3.34)$ & & $0.05(6446)$ & $0.09(0.01-0.93)$ & \\
\hline $1994-2$ & $0.45(7857)$ & $0.73(0.17-3.07)$ & & $0.03(7033)$ & $0.05(0.00-0.63)$ & \\
\hline $1995-1$ & $0.47(8875)$ & $0.81(0.19-3.39)$ & & $0.13(6925)$ & $0.25(0.03-2.24)$ & \\
\hline $1995-2$ & $0.50(9453)$ & $0.83(0.20-3.47)$ & & $0.05(7935)$ & $0.09(0.01-0.95)$ & \\
\hline $1996-1$ & $0.59(9558)$ & $0.97(0.23-4.05)$ & & $0.06(8477)$ & $0.11(0.01-1.08)$ & \\
\hline $1996-2$ & $0.53(8607)$ & $0.87(0.21-3.65)$ & & $0.10(7703)$ & $0.17(0.02-1.58)$ & \\
\hline
\end{tabular}

*Adjusted for age, IDU, time (as a factor), and centre.

†Not asked or not recorded. 
Table 4 Seroprevalence of HIV-1 infection among homosexual and bisexual men aged 25 or less

\begin{tabular}{|c|c|c|c|c|c|c|}
\hline & \multicolumn{3}{|l|}{ London } & \multicolumn{3}{|l|}{ Outside London } \\
\hline & $\begin{array}{l}\% \text { HIV-1 } \\
\text { infected (total) }\end{array}$ & $\begin{array}{l}\text { Adjusted OR* } \\
(95 \% \mathrm{CI})\end{array}$ & $p$ Value & $\begin{array}{l}\% \text { HIV-1 } \\
\text { infected (total) }\end{array}$ & $\begin{array}{l}\text { Adjusted OR* } \\
(95 \% \mathrm{CI})\end{array}$ & $p$ Value \\
\hline \multicolumn{7}{|l|}{ Age group } \\
\hline$<20$ & $4.95(364)$ & $0.80(0.48-1.32)$ & 0.3698 & $0.92(435)$ & $0.43(0.15-1.23)$ & 0.0822 \\
\hline 20 to 24 & $5.83(3226)$ & 1.00 & & $2.16(1624)$ & 1.00 & \\
\hline \multicolumn{7}{|l|}{ IDU } \\
\hline Yes & $12.26(106)$ & $2.13(1.15-3.94)$ & 0.0645 & $0.00(40)$ & $0.00 \ddagger$ & 0.2527 \\
\hline No & $5.44(3293)$ & 1.00 & & $1.88(1967)$ & $1.00^{\circ}$ & \\
\hline $\mathrm{NA} / \mathrm{NR} \dagger$ & $7.33(191)$ & $1.29(0.72-2.32)$ & & $3.85(52)$ & $2.10(0.46-9.67)$ & \\
\hline \multicolumn{7}{|l|}{ Year } \\
\hline 1990-1 & $4.17(96)$ & 1.00 & 0.1117 & $8.33(24)$ & 1.00 & 0.5461 \\
\hline 1990-2 & $10.92(238)$ & $2.15(0.72-6.45)$ & & $3.37(89)$ & $0.49(0.07-3.32)$ & \\
\hline $1991-1$ & $6.48(293)$ & $1.30(0.42-3.96)$ & & $2.13(94)$ & $0.29(0.04-2.33)$ & \\
\hline 1991-2 & $8.21(207)$ & $1.79(0.58-5.50)$ & & $5.32(94)$ & $0.66(0.11-4.06)$ & \\
\hline $1992-1$ & $10.00(150)$ & $2.22(0.71-6.95)$ & & $0.77(130)$ & $0.09(0.01-1.08)$ & \\
\hline $1992-2$ & $7.90(291)$ & $1.59(0.53-4.79)$ & & $1.27(157)$ & $0.17(0.02-1.42)$ & \\
\hline 1993-1 & $5.16(194)$ & $1.04(0.31-3.45)$ & & $0.47(214)$ & $0.07(0.01-0.84)$ & \\
\hline 1993-2 & $4.86(185)$ & $0.97(0.29-3.30)$ & & $2.07(193)$ & $0.29(0.04-2.02)$ & \\
\hline $1994-1$ & $5.50(182)$ & $1.15(0.35-3.81)$ & & $1.56(192)$ & $0.24(0.03-1.77)$ & \\
\hline 1994-2 & $4.06(345)$ & $0.89(0.28-2.81)$ & & $1.65(182)$ & $0.24(0.03-1.72)$ & \\
\hline 1995-1 & $4.33(416)$ & $0.97(0.32-2.99)$ & & $1.68(179)$ & $0.24(0.03-1.74)$ & \\
\hline 1995-2 & $3.34(359)$ & $0.74(0.23-2.39)$ & & $1.97(152)$ & $0.28(0.04-2.09)$ & \\
\hline $1996-1$ & $4.66(386)$ & $1.12(0.36-3.45)$ & & $2.54(197)$ & $0.32(0.05-2.08)$ & \\
\hline $1996-2$ & $4.44(248)$ & $0.95(0.29-3.11)$ & & $1.23(162)$ & $0.15(0.02-1.27)$ & \\
\hline
\end{tabular}

*Adjusted for age, IDU, time (as a factor), and centre.

†Not asked or not recorded.

$¥$ Adjusted OR estimate very low with confidence interval $(-\infty,+\infty)$ as no IDU was HIV positive.

HOMOSEXUAL AND BISEXUAL MEN AGED UNDER 25 YEARS

There was no difference in prevalence between the under 20 and the 20-24 year olds either inside London ( $4.95 \%$ and $5.83 \%$ respectively) or outside London $(0.93 \%$ and $2.16 \%$ respectively) and, over the 7 year period, there was no trend in seroprevalence either inside or outside London (table 4). Although seroprevalence of undiagnosed HIV-1 infection was twice as high in those who injected drugs, this difference was not significant $(\mathrm{p}=0.06)$.

\section{Discussion}

Undiagnosed HIV-1 infection is important both to public health and to the surveillance of HIV. Identifying undiagnosed infections enables individuals to benefit from advances in treatment and care, and reduces the risk of transmission to HIV negative partners. However, it has been suggested that detection of HIV infection in UK clinics may be lower than in some other European countries. ${ }^{13}$ This analysis provides evidence that many infections remain undiagnosed after individuals have attended a GUM clinic. This is disturbing and supports the view that voluntary confidential testing should be strengthened in GUM clinics to increase the chance of early diagnosis. ${ }^{14}$

Over the period studied there was no indication of infection spreading beyond known risk groups. The contrast between London and other areas in terms of detected prevalence also indicates that infection has not diffused beyond the London area since the early 1990s. The HIV epidemic is focused on homosexual and bisexual men, the highest seroprevalences of undiagnosed HIV-1 infection were seen in this exposure category. The substantial burden of undiagnosed HIV-1 infection indicates that homosexual and bisexual men continue to place themselves at risk of HIV-1 infection despite public health campaigns, an observation which has been made in behavioural and seroprevalence studies both in the United Kingdom and elsewhere. ${ }^{15-17}$ The acquisition of STIs by homosexual and bisexual men who are aware of their HIV infection, indicates that knowledge of HIV infection status does not eliminate behaviour associated with continuing risk of HIV transmission. $.^{70} 16-18$

The seroprevalence of undiagnosed HIV-1 infection could have been influenced by variations in study selection procedure but no evidence was found in any of the survey's audit studies. Similarly, the seroprevalence of both diagnosed and undiagnosed HIV-1 infection could have been influenced by variations in testing practice but this is unlikely to have occurred as no changes were made to national testing policy during the period included in this analysis.

The reduction in seroprevalence of undiagnosed HIV-1 infection in homosexual and bisexual men needs to be carefully interpreted. Declines have been seen in other countries but, as most studies do not record diagnostic status, these observations could be accounted for by variations in diagnosis and care. ${ }^{16}{ }^{17}{ }^{19}$ Since this study is based on undiagnosed infection, variations in case management (that is, the opening of specialist services attached to clinics taking part in the study) cannot account for the fall. Nor can it be explained by increasing diagnoses as the proportion of recognised infections has not changed in recent years. ${ }^{10}$ This study shows continuing transmission and incidence, indicated by the consistent, substantial seroprevalence of undiagnosed HIV-1 infection among homosexual and bisexual men under 25 years of age and data from voluntary confidential HIV-1 testing and incidence studies. ${ }^{20}$ Younger men are thought to have unsafe sex because they are less experienced in personal and/or sexual negotiation. ${ }^{16}{ }^{18}{ }^{21}$ Clearly, HIV prevention needs to target this group. Variations in transmission in older age groups remains unclear but the use of tests to distinguish 
recently acquired infection may be able to provide more information in this area. ${ }^{14}$

Although seroprevalence of undiagnosed HIV-1 among heterosexuals was lower than homosexual and bisexual males, the significant increase among heterosexual males inside London and the stable seroprevalence among females is of particular concern. Sex between men and women accounted for $16 \%$ of AIDS cases and $20 \%$ of diagnosed HIV-1 infections to the end of $1997,{ }^{1}$ but heterosexual transmission is considered uncommon in England and Wales. Sixty five per cent of AIDS case reports probably acquired through sexual intercourse between men and women have been associated with exposure in Africa, the majority were reported from London. ${ }^{1}$ Country of birth data would allow a more comprehensive analysis of the heterosexual data but is only available for two of the seven years of the study and consequently was not included in this analysis. However, analysis of the available country of birth data indicates there was no difference in the proportion of undiagnosed HIV-1 infection by world region of birth for homosexual and bisexual men or heterosexual men or heterosexual women. ${ }^{22}$

This study highlights the continuing problem of undiagnosed HIV-1 infection among attenders at GUM clinics, a problem which has also been recognised in pregnant women. ${ }^{23}$ Methods of offering HIV testing need to be reassessed if awareness to the benefits of HIV testing is be improved.

This survey would not have been possible without the support of clinical, clerical, and laboratory staff at clinics and hospitals, whose help is gratefully acknowledged. The development of this survey, and others in the HIV prevalence monitoring programme in England and Wales, benefited from discussions with colleagues at the Scottish Centre for Infection and Environmental Health and Dr AV Swan (PHLS Statistics Unit).

Survey collaborators group:

The members of the survey group from 15 clinics and associated laboratories comprised: BS Azadian, FC Boag, P Carey, C Carne, D Carrington, E Claydon, PV Coyle, F Davidson, I Farrell, G Kinghorn, G Kudesia, R Maw, D Mercey, A McManus, PR Mortimer, J Munro, S Murphy, K Mutton, M Nathan, L Neville, A Pozniak, JD Ross, N Sankar, G Scott, MS Shafi, S Skidmore, R Sparks, A Turner, A Wade, P Watkins, P Wilson, T Wreghitt, and M Zuckerman.

Support for the survey was provided by the Department of Health both directly and through the Medical Research Council.

1 PHLS AIDS and STD Centre-Communicable Disease Surveillance Centre, and Scottish Centre for Infection and Environmental Health. Unpublished Quarterly SurveilEnvironmental Health. Unp
lance Tables No. 43, 99/1.
2 United Kingdom Departments of Health. HIV and AIDS health promotion: an evolving strategy. London: Department of Health, 1995.

3 Parry JV, Mahoney A, Mortimer PP. Are seroepidemiological surveys for human immunodeficiency virus infection based on tests on pools of serum specimen accurate and cost-effective? Clin Diagn Virol 1993;1:167-8.

4 Johnson AM, Wadsworth J, Wellings K, et al. Sexual attitudes and lifestyles. Oxford: Blackwell Scientific Publications, 1994.

5 Simms I, Hughes G, Swan AV, et al. New cases seen at genitourinary medicine clinics: England 1996. Commun Dis Rep Suppl 1998;8:S2-S11.

6 Macdonald ND. AIDS and HIV infection acquired through sexual intercourse between men. Commun Dis Rep CDR Rev 1997;7:123-4

7 Gill ON, Adler MW, Day NE. Monitoring the prevalence of HIV. Foundations for a programme of unlinked anonymous testing in England and Wales. BMF 1989;299:12958

8 Catchpole MA, Mercey DE, Nicoll A, et al. Continuing transmission of sexually transmitted diseases among patients infected with HIV-1 attending genitourinary medicine clinics in England and Wales. BMf 1996;312: 539-42.

9 Ades AE. Serial HIV seroprevalence surveys: interpretation, design, and role in HIV/AIDS prediction. $\mathcal{F}$ Acquir Immune Defic Syndr 1995;9:490-9.

10 Department of Health, Public Health Laboratory Service, Institute of Child Health. Prevalence of HIV in England and Wales in 1996. Annual report of the Unlinked Anonymous Seroprevalence Monitoring Programme in England and Wales. Seroprevalence Monitoring Programme in

11 Francis B, Green M, Payne C, eds. The GLIM system release 4 manual. Oxford: Oxford University Press, 1993.

12 Duong T, Ades AE, Rogers P, et al. Non-participation bias in unlinked anonymous surveys in England and Wales. Epidemiol Infect 1999;122:267-72.

13 European Centre for the Epidemiological Monitoring of AIDS: HIV/AIDS Surveillance in Europe. Knowledge of
HIV seropositivity before AIDS diagnosis. Quarterly Report No 52. Saint-Maurice: European Centre for the Epidemiological Monitoring of AIDS, 1997.

14 DeCock K, Johnson AM. From exceptionalism to normalisation: a reappraisal of attitudes and practice around HIV testing. BMF 1998;316:290-3.

15 Hickson FCI, Reid DS, Davies PM, et al. No aggregate change in homosexual HIV risk behaviour among gay men change in homosexual HIV risk behaviour among gay men attending the Gay Pride festival

16 Torian LV, Weisfuse IB, Makki HA, et al. Trends in HIV seroprevalence in men who have sex with men: New York City Department of Health sexually transmitted disease clinics, 1988-1993. AIDS 1996;10:187-92.

17 Fennema JSA, van Ameijden EJC, Coutinho RA, et al. HIV surveillance among sexually transmitted disease clinic attenders in Amsterdam, 1991-1996. AIDS 1998;12:931-

18 Osmond DH, Page K, Wiley J, et al. HIV infection in homosexual and bisexual men 18 to 29 years of age: the San Francisco young men's health study. Am $\mathcal{F}$ Public Health 1994;84:1933-7.

19 Nardone A, Rogers P, Joyce C, et al. The interpretation of trends in HIV seroprevalence amongst homo/bisexual men attending a GUM clinic in central London. MRC AIDS Research Workshop Abstract Book, 1995;4-5:29.

20 Miller E, Waight PA, Tedder RS, et al. Incidence of HIV infection in homosexual men in London, 1988-94. BMF 1995;311:545.

21 Ridge DT, Plummer DC, Minichiello V. Young gay men and HIV: running the risk? AIDS Care 1994;6:371-7.

22 McGarrigle C, Nicoll A. Prevalence of HIV-1 among attenders of sexually transmitted disease clinics: analysis according to country of birth. Sex Transm Inf 1998;74:41520.

23 Nicoll A, McGarrigle C, Brady AR, et al. Epidemiology and detection of HIV-1 among pregnant women in the United Kingdom: results from national surveillance 1988-96. BMF 1998;316:253-9. 